\title{
Analysis of Public Participation on Budget Implementation in Kisii County Government, Kenya
}

\author{
Joseph Wesonga Awire Simon Nyakwara $^{2}$ \\ 1. Masters Degree in Business Administration and Management of Mount Kenya University \\ 2. Doctor of Philosophy\& Director at Kisii Campus of Mount Kenya University
}

\begin{abstract}
The budget is an integral energy in every facet of the economy of any country. Budgeting is a significant tool in corporate institutions for directing activities and employees' efforts toward the organization's common objectives or in actualizing corporate goals in defined timeframe. While the reform of bureaucracy was not initially considered to be a vital element of participatory budgeting programs, it has emerged as an unintended consequence that strongly influences the success of the process. Decentralization allows for targeted information to be provided to relevant groups. Through the branch offices, technocrats develop better ideas of the types of information participants need to make informed choices. Information about drainage and water flows; citizens in the urban center require information about the costs and complexities of overhauling decaying infrastructure. Participatory budgeting contributes to administrative reform is by integrating different bureaucratic units into the policy-making and implementation processes. Administrative agencies such as the departments of health or education cannot operate as isolated units within the participatory budgeting process. They must work closely with the planning agency and with participatory budgeting participants to define their policy agendas. New investments cannot generally be undertaken without the explicit approval of participatory budgeting participants and implementation done in every stage. Budgeted results communicate to employees the organization's expectations regarding their job performance, which is evaluated based on some comparison of actual versus budgeted results. Kisii County is no special case to spending plan failure and its execution which can be measured in terms of achievement needs. The purpose of the research was to analyse public participation on budget implementation in county governments in Kenya by taking a selected case of Kisii County. The study population was representatives of the populace of kisii and authorities of the Kisii County. A sample size of 105 respondents was used in the study while questionnaire was used as research tool. The study established that public participation positively and significantly influence budget implementation at $\mathrm{r}=.443 * *$ and $\mathrm{p}<.05$ significant level. The study recommends that the County governments should create rules to support Economic and Social Rights Center, 2013 which demands the general population inclusion to incorporate their views in the County Integrated Development.
\end{abstract}

Keywords: Public participation, Budget implementation, Kisii County Government, Kenya.

DOI: $10.7176 / \mathrm{EJBM} / 11-29-09$

Publication date:October $31^{\text {st }} 2019$

\subsection{Background to the study}

A budget is an integral part whose facet of the economy can not be undervalued. It is that unbiased financial fit, measuring the operation that gears the fiscal wellbeing of the organization (Seer 2000), also according to Reid (2002) it presents the prospects of An organization in monetary terms for a future period of time. Administrative reform is creates a more transparent relationship between the business community and the government. Participatory budgeting establishes projects that will be implemented over a two- or three-year period. Contractors and builders know which projects will be implemented and are able to plan more efficiently. The fact that bribes no longer have to be paid to have a project implemented reduces the cost of business, increases profit margins, and fosters governmental credibility.

The setting up of a budget is vital to the efficient operation of any organization, since it enhances the accomplishment of various tasks. According to Lin and Chang (2005), a budget is not just a tool for planning (projected revenue and expenditure of a period) but also a control device used in organizations. It enhances the coordination of activities within that institution, and promotes communication amongst stakeholders.

Budgetary participation as defined by Shields and Shields (1998) is the process where a manager is fully part of, effects and controls, his or her budget. The history of examining the connection between budget participation and performance dates back to managerial accounting literature (Leach-Lopez, Stammerjohan, \& McNair, 2007) and as a matter of fact budget participation has been one of the most explored topics in management accounting in the last 40 years (Shields \& Shields, 1998; Eker \& Eker, 2008). It discloses the extent managers take part in budget setting

(Subramaniam \& Mia, 2001; Parker and Kyj ,2006) providing an upright channel for information-sharing that is, an upward information dissemination strategy from subordinate to superior and a downhill communication from superior to subordinate, making both the superiors and subordinates completely part of the budget process (Weil \& Maher, 2005). 
Robinson (2007), in developing countries, the organization of budgetary system is subordinated to the problems of eliminating the remnants of feudalism and colonialism. In view of the weakness of the inadequacy of their capital, the most important measures in the areas of economics and culture in these countries such as India, the Arab Republic of Egypt and others were financed through the state budget. 2 At the same time, in order to involve broad layers of the population in the accomplishment of national economic and political tasks, the governments of these countries follow a policy of developing the plan and budget capital of local bodies.

Budget participation and its effect on managerial performance have been reviewed by various researchers with most literature supporting the thought that participative budgeting significantly and positively affects performance (Nouri \& Parker 1998; Kren 1992 and Parker \& Kyj, 2006).

Nouri and Parker (1998) critically evaluated the relationship between organizational commitment, as well as budget adequacy as an intervening variable in the budgetary participation - job performance relationship. A survey of 139 American managers and supervisors from large corporations was used. They found that there was a direct association between the subject matter under review. Charpentier (1998) argued that active contribution to the budget enhances workers' budget goal, commitment and ultimately improved performance. Chong and Chong (2002) also established that budget affects subordinates performance through information sharing, control and trust, which has bearing of increased commitment (Chong \& Johnson, 2007; Subramaniam \& Mia,2001).

The principle capacity of a financial plan in any association is for arranging and controlling, to accomplish hierarchical objectives and targets (Schick, 1999). Spending execution has been for an excessive number of years seen fundamentally as a procedure worried about the pre review of bank bills and strategies of their installment (Berg and Skogley, 2002). In any case, in all actuality spending usage and related parts of money administration are more than the aggregate of the above components (Zimmerman, 2003).

However according to (Brian 2007), lack of a strong commitment to participatory budgeting by government leaders makes it difficult for participatory budgeting programs to succeed. In Recife, for example, the mayor began to use participatory budgeting as a means to distribute public monies for the yearly carnival. Instead of holding open, transparent meetings, he manipulated the release of funds so that "friendly" participants would benefit. Nonparticipating citizens and "unfriendly" citizen-delegates did not have access to the public resources. Participatory budgeting participants expressed concern that if they did not act a certain way they would be "boycotted" by the government. This does little to empower citizens and may just be a new form of clienteles' ownership. Sometimes governmental actors are hostile to participation, viewing it as a threat to their institutional rights and privileges. In other cases governments may not be opposed to participation, but they are skeptical of it, unsure how it works and what benefits it provides beyond symbolic ones.

Heimans, (2002) opines that a more common perspective among developing-country governments sees participation in the budget process as being politically obligatory, or even politically advantageous, but of little practical significance. Governments use participatory rhetoric and limited gestures toward increased budget transparency and community budget consultations to assuage donors and reduce tensions with civil society, but they may not meaningfully engage with the process - at least initially. (Heimans 2002, p. 15)

For a successful operation of business, budgeting constitutes an essential exercise which if not in existence could hinder the achievements of a firm or business. It is a management tool used mostly by firms in processing information and reports to top managements for forecasting and control purposes (Yuen, 2007; Drury, 2008; Weetman, 2006), hence the need to involve stanch subordinates in this process in order to influence organizational output. Organizations encourage participation in the budgetary processes because it is argued that it draws into play various benefits which include an increase in employee motivation and commitment, talents among employees, enhanced sense of responsibility, job satisfaction and a speedy performance (Weil \& Maher, 2005).

New legitimate casing work established by the new constitution, regions are encountering challenges in executing spending plans and subsequently there are big dissimilarity between the province spending plans and achievements. A few surveys of PFM in creating nations demonstrate that nations score preferable on spending planning over on spending execution markers (Andrews, 2008). As indicated by Sayeh (2013), large scale financial solidification in Kenya was joined by changes in fundamental spending capacities. A key test in Kenya will be to execute basic PFM hones in the new Counties that have been set up bringing about the decentralization activity reflected in the new constitution. Suberu (2010) states that for any association to perform successfully, spending plan and planning ought to enable operational use of existing assets enhance basic leadership, give a seat check to quantify and control execution, enhance correspondence and investigation in the association and create understanding between supervisors about objectives and destinations.

According to the Government of Kenya (2010) the constitution develops open collaboration as one of the important rights of the Kenyan people. Segment 11 of the constitution, which discusses Devolved governments conclusively; express the criticalness of national enthusiasm for the endeavors of government. Article 196 on open help and area gathering powers, advantages and resistances evidently stipulate that the local government ought to support open venture and commitment in the regulatory and diverse business of the region get together and its committees (GoK 2010). 
Article 174 of the constitution gives the vitality of self-organization to all-inclusive community of Kenya and advances the help of the locals in exercise of the vitality of the state and in settling on decisions on issues that impact. Planning is a basic movement of any administration world over. Through the procedure, the legislature can decipher the utilization of physical assets to meet national needs and satisfy their guarantee to the electorate. Subjects on their part expect the way toward planning to be reasonable, straightforward, and impartial (OECD, 2007). 10 years prior, the reasoning on planning among technocrats, macroeconomic approach producers and scholastics supported for a procedure that was embraced solely by technocrats in the Ministries of Finance and Ministries of Planning. The inclination was to do a procedure without "governmental issues" (World Bank, 2002)

As per Olurankise (2012), budget making and spending usage includes the procedure of distinguishing proof of open needs by the political procedure, by financial examination with the general advancement goals. Once a financial plan has been affirmed by the council, the legislature sets out on the testing undertaking of spending reserves.

Spending open supports successfully to meet expressed strategy targets while guaranteeing an incentive for cash is frequently only as challenging than arranging how to spend it (Rebecca et al, 2011).

In Porto Alegre, Brazil, governments not only welcomed but promoted participatory budgeting. An election platform based on spending changes and enhancing citizen involvement created favorable political conditions. The fact that the government was bankrupt increased the willingness to experiment with new forums, and the disorganization of the bureaucracy weakened resistance to change. The government was also willing to increase revenues that could be applied toward proposals from participation forums, which immediately made participation significant. The Workers' Party changed the municipal revenue system by indexing property taxes, "widening the fiscal space that was a necessary precondition for participatory budgeting"

(Robinson 2004). Modeled on the same pedestal, Kisii County Government executes her strategies through its financial plan without much success hence Porto's Alegre experience points to the importance of political parties in prompting adoption of public participation in budget implementation in Kisii County.

\subsection{Statement of the problem}

Governments not only welcome but promote participatory budgeting on economic activities or a social justice agenda. The success of participation depends in part on administrative capacity. In Porto Alegre the bureaucracy played a positive role in organizing meetings, providing necessary information to citizens about their choices, and offering technical analyses for project proposals. To provide support at the neighborhood level, more government offices were opened in new areas of the city. The decentralization of physical locations was a very visible indicator of government accessibility. Meetings were decentralized and easily accessible to all who wanted to attend. Wampler (2000) opines that the nature of citizen proposals forces bureaucracies to think more collaboratively. A proposal on health or health requires the departments concerned to work with the planning agency and with community leaders. Technical plans and new investments usually require the approval of participants and foster an ongoing relationship based on open Modeled on the same. The financial plan whether it is for an open organization or for a private increase situated organization is a fundamental and effective apparatus in administration and fills in as a device for arranging and controlling the utilization of restricted money related resources.

Administrators may argue that participation reduces the quality of the decision outcome, poor decisions are made because of lack of knowledge or expertise on the part of the public (Cleveland 1985). A frequently cited explanation for governments' resistance to participatory budgeting is that it will make tough choices on the distribution of resources even more difficult despite the constitutional pronouncement of 2010 on the same, hence the justification of the study.

\subsection{LITERATURE REVIEW}

\subsection{Participatory budgeting programs on Budget Implementation}

While many participatory budgeting programs address the overall financial health of the municipality, the principal focus remains discretionary spending. Having discretionary funding available is important because it increases the likelihood that citizens can directly select policy outcomes. The more financial flexibility a government enjoys, the greater the influence citizens can exercise on the selection of new public works. Governments must have the resources to implement the projects that participants select. If a financially strapped municipality decides to implement a participatory If a financially strapped municipality decides to implement a participatory budgeting program, the focus shifts from the selection of specific public works projects to a more general discussion of debt, taxes, and the efficient use of limited resources. The municipal government must first dedicate considerable time and energy to explaining to participants the dire financial situation of the municipality. Participants must then vote on the general policy priorities of the government. Participants will not select specific public works to be implemented but will indicate in a broad fashion how the government should spend available resources (Donald 2007). 


\subsection{Constitutionalism of Participatory budgeting programs on Budget Implementation}

Kenya's 2010 Constitution and succeeding enactment, for example, the County Governments Act and the Public Finance Management Act, require open involment in issues of open fund. While there are many references to open support in these laws, most are obscure and contain no further direction. There is one noteworthy avoidance to this, notwithstanding, which is the particular commitment that each area should set up a County Budget and Economic Forum (CBEF). The CBEF is approved by the Public Finance Management (PFM) Act, 2012. The Act,which states that regions might make these gatherings keeping in mind the end goal to give an intend to discussionby the province government on readiness of district strateic plans, Review and Outlook Paper for the area ,the County Fiscal Strategy Paper, and the Budget; and matters identifying with planning, money related administration and the economy at the region level (Lakin, 2013).

Studies directed by the Haggard and Webb (1994) contend that thus, government officials delegated decisionproduction expert to technocrats who were protected from weight and impedance from intrigue gatherings, the assembly, and bureaucratic procedures. Observational discoveries on this issue were in opposition to this contention. Concentrates by the World Bank (2002) discovered that a more comprehensive approach with key partners including people in general would upgrade the maintainability of arrangements and enhance their prospects for usage achievement. South Africa's Constitution of 1993, the Municipal Structures Act of 1998, the Municipal Systems Act of 2000, the Municipal Finance Management Act of 2003, and the Municipal Property Rates Act of 2004 all contain provisions promoting two primary forms of participation at the local government level. The first mechanism, the ward committee system, is designed to provide a forum in which communities can play an active role in their municipality. Each ward directly elects a ward councilor, who represents the ward's interests as a member of the municipal council. The second mechanism, the su-bcouncilors, comprises ward councilors as well as other councilors appointed by the council to ensure equal political party representation. Additional participatory mechanisms are available to each municipality.

\subsection{Participatory budgeting programs process \& procedures on Budget Implementation}

Over the most recent two decades, some Latin American nations have actualized participatory planning as a method for fusing native's points of view into spending making keeping in mind the end goal to expand resident's entitlement to take part and improve straightforwardness. Some of these nations incorporate Argentina, Bolivia, Brazil, Chile, Colombia, Ecuador, El Salvador, Dominican republic, Guatemala, Mexico, Paraguay, Nicaragua, Peru, Uruguay, and Venezuela. By the year 2007, 2,500 nearby governments in these nations were executing participatory planning with awesome achievement (ELLA, 2012). As of late, open support in thebudgeting process is established upon standards, for example, Legitimacy, Accountability and straightforwardness in basic leadership, inclusivity and reasonableness (Economic and Social Rights Center, 2013).

Kenya was among the main nations in Africa other than South Africa to make open interest in planning an established prerequisite (Economic and Social Rights Center 2013) Kenyan constitution authorized in 52010 digs out in the open investment as one of the principal benefits of the Kenyan individuals. Section 11 on Devolved governments particularly explains the significance of native cooperation in the undertakings of government. This is illustrated in supplement five. Article 196 on open investment and area get together powers, benefits and resistances plainly stipulate that the province government might encourage open support and association in the administrative and different business of the region get together and its boards of trustees (Government of Kenya, 2010).

Article 201 of the Kenyan constitution explains a portion of the key open fund standards including the requirement for straightforwardness out in the open back issues. The standards likewise accentuate that open support might be advanced in the basic leadership and planning process (National Taxpayers Association, 2013) The Kenya's Public Financial Management (PFM) Act, which was marked into law by the President in July 2012, gives the lawful system to the investment of the general population in planning and guaranteeing responsibility in budgetary administration. The Bill makes a few references to the need to guarantee open support in various money related administration forms. (Legislature of Kenya, 2014) the Parliamentary Budget Office is relied upon to "watch the rule of open support in budgetary issues" (10:2) The Treasury is expetedto "seek after and think about the feelings of people in general" in putting forth the Budget Policy Expression consistently (25:5). This demonstration over and over makes reference to the part and criticalness of general society cooperation in planning and budgetary administration. The PFM demonstration additionally made the County Budget and Economic Forum (CBEF) whose central capacity is to assemble open interviews on budgetary issues at the district level (Government of Kenya, 2014).

As indicated by McNulty (2007), participatory procedures are just endurable if individuals feel that their inclusion matters. On the off chance that there is no confirmation that involvent has any effect on what government does or how it does it, individuals will quit contributing. This issue is one of execution as well as torment meeting forms where there is no plainly characterized result. As noted before, the "work of art" model of participatory planning has the favorable position that it brings about simple to recognize ventures. More extensive interviews 
once in a while miss the mark regarding individuals' foresights since it's not clear how their exertion was thought about. It's, therefore,essential to consider how division and entire spending plan ways to deal with theconsultation can coordinate particular yields and criticism on inputs given. In Hilden, Germany, every member who makes a contribution at city spending interviews gets an individual card demonstrating whether their proposal was utilized or not, and in the event that it will be actualized, when (GIZ, 2009).

\subsection{Participatory budgeting Spending on Budget Implementation}

Kenyans have profound and long-lasting worries about the routes in which assets have been distributed across the nation. Numerous areas and individuals feel that they have been surrendered by a solid focal administration. The cure in the 2010 Constitution is, from one viewpoint, devolution of energy to bring down level government and, then again, endeavors to open up establishments at all levels and surge the open doors for open support, and more prominent checks by new bodies, for example, the Controller of Budget (Public Finance Management-PFM, 2013).

It takes after from this that open commitment is to a limited extent about bringing into line the necessities and needs of general society all the more intimately with the decisions of government authorities. This suggests open interest must occur at the detailing and endorsement periods of the financial plan, when urgencies are being set. At this progression, open commitment can support basic leadership by passing on data about open requests to the consideration of lawmakers as they organize their spending. This can prompt a more evenhanded dispersion of assets (Lakin, 2013).

Likewise, concerns emerging from corruption and inability to legitimize for assets over the span of spending plan execution recommend that open investment in Kenya is additionally urgent amid spending execution and when spending execution is evaluated. The overall population has a very important part to play that supplements the County Assembly and different bodies. Data that the general population holds about the success of open expenditure on the grass root can help in advising the oversight procedure and enhance spending usage. It is concluded from this that open cooperation is indispensable at all means of the spending procedure. Open support is likewise about building the authenticity and validity of the government. By drawing in heartily with nationals, government authorities can guarantee support for their projects and construct trust in the capability of the administration. This can inspire investors to confer reserves, urge natives to pay expenses, and benefactors to top up existing wellsprings of pay. In the event that we consider public interest as a device for building authenticity and believability, this indicates that powerful cooperation will need transparency and an efficient criticism circle in which subject's requests are answered to, and reasons are accommodated consolidating or not joining them (Ebdon and Franklin, 2005).

At the point when individuals contemplate on open investment, they regularly consider gatherings. An open discussion is generally open to any individual who needs to go to. Presently, we realize that albeit open discussions are interested in everybody, not every person comes. The general population who go to are here and there the general population who live nearest to the setting, or the individuals who get earlier information about the discussion, or the general population who can manage the cost of time off the work schedule to go to. It in this way takes after that even an open gathering who exclude everybody. This can be partly moderated by enabling individuals to send composed entries or by holding open discussions at the most minimal level conceivable. There are different approaches to compose open verbal confrontation past merely holding open discussions. For example, even in Kenya's own insight with participatory planning, the Local Authority Service Delivery Action Plan (LASDAP), open exchange was sorted out at numerous levels and assignments were utilized. At first, conference gatherings were called at the ward level. At that point, two individuals (one male and one female) were selected to speak to the ward at the neighborhood specialist level "agreement" gatherings. This approach, which was obtained partially from Brazil, can be reached out to different levels, with selections from the most reduced levels (e.g., town) to the most noteworthy (e.g., area, or even national). This can enable individuals to take part more extensively regardless of the possibility that they are absent (Nivek, 2012).

Experience from Kenya and all over the world recommends that building up aparticipatory systems is faced with difficulties, and interest activities frequently flounder. It's imperative to be aware of these difficulties from the earliest starting point keeping in mind the end goal to in any event endeavor to plan for them.Access to data and comprehension is regularly a test. Spending data is oftenlydifficult to accomplish, and difficult to get it. On the off chance that contribution components are to work, there must be a greatextent of straightforwardness, however existinginformation ought to likewise be delivered in a way that is basic and straightforward. In different settings, extraordinary activities have been taken to guarantee that data is accessible and is in a simple to utilize design. In the Philippines, the Budget Partnership Agreements between common society and government organizations incorporate particular revelation necessities (e.g., spending data from the most recent five years) to encourage support. In Burlington, Iowa (USA), the administration chooses a Citizen Budget Education Committee to guarantee that spending data is rearranged for open utilization. Essentially in German towns, for example, Hilden, the town readies a pamphlet with key spending information, and afterward there are data remains at open gatherings themselves where individuals can get additional data (Ebdon and Franklin, 2005). 
Activation of members can't be expected in the spending making process. Any way to deal with support requires individuals to be educated, however to a great extent likewise to be assembled. An unobtrusive commercial in the day by day paper, or even open notice sheets all the more broadly conveyed, are regularly not adequate to inspire individuals to go to or take an interest in discussions, especially in settings with a protracted history of avoidance. In situations where participatory methodologies have been productive, government or common society associations have much of the time put considerable assets into assembly. In New York City a nearby respectful society association, Community Voices Heard, assumed a key part in effort to underestimated bunches for participatory planning. In Brazil common society gathers open gatherings preceding authority discussions to cause set up the general population to participate in gatherings. In Kerala, India, government supported an immense effort crusade including 50,000 nearby activists (in a state with a populace of 30 million) to prepare natives for participatory planning (Lerner and Secondo, 2012). So as to warrant that the recommendations made by general society through participatory instruments are steady with what is fiscally and in fact doable, it's important to have a specialized group engaged with the procedure. For example, the LASDAP procedure in Brazil incorporated a Technical Committee expanding on the Brazilian participatory planning background. This is a key piece of the Peruvian approach, too. In the truancy of a specialized survey process, expulsion of undertakings will be viewed as politically prompted. Moreover,bulding and keeping up a specialized audit process needs assets and limit with respect to the administration.

It is conceivable to enable subjects to contend the whole spending plan, over all segments and both rehashed and improvement spending. This has been done in Australia and China at neighborhood levels. In Canada Bay, Australia, an agent smaller than normal open was welcome to ponder on the whole (four-year) spending plan (Nivek, 2012). The town of Zeguo in China made a smaller than normal open, too, and has investigated various methodologies, including a level headed discussion of the full spending plan in 2009. There is a naturalbenefit to the blend of a small open and a full dabate of the financial plan since a smaller than expected open can be accurately informed and finished to permit more unpredictable exchange than a common open gathering (Yan-Wu and WanYeng, 2012).

\subsection{METHODOLOGY \\ 3.1 Research Design}

Research configuration is the general arrangement for associating the calculated research issues to the germane and achievable exact research. Mugenda and Mugenda (2005) shows that exploration configuration verbalizes what information is required, what techniques will be utilized to gather and dissect this information, and how the greater part of this will answer the analysts question. The investigation will utilize a contextual investigation as its examination outline. As indicated by Cooper, and Schindler (2006) a contextual investigation is a capable research system that consolidates individual and (now and again) gather interviews with record examination and perception. It is utilized to comprehend occasions and their implications and procedures. Mugenda and Mugenda (2005) portray a contextual investigation as an inside and out examination of an individual, gathering, organization or marvel. A contextual investigation approach is appropriate to decide the elements that make a specific passage system great for the association under examination.

\subsection{Population of the Study}

According to Kombo and Tromp (2006), populace is a gathering of people, articles or things from which tests are taken for estimation, or, it is a whole gathering of people or components that have no less than one thing in like manner. The objective populace of the examination will be all the every one of the representatives and authorities of the Kisii County. Target populace is characterized as that populace to which an analyst needs to sum up the aftereffects of the examination.

\subsection{Sample and Sampling Procedure}

This examination will receive the stratified arbitrary inspecting strategy. Irregular testing gives an analyst a reasonable or agent perspective of the whole populace. What's more, this method empowers the specialist to have a top to bottom investigation and knowledge on the subject being contemplated (Merriam, 2003). A specimen must be painstakingly chosen to be illustrative of the populace and the analyst additionally needs to guarantee that the subdivisions involved in the examination are precisely provided food for. Arbitrary testing strategy will guarantee diverse subgroups in the Kisii County representatives and authorities are spoken to in the examination.

A specimen of 105 representatives and authorities will be drawn from among the County specialists and authorities. An example can be characterized as a limited piece of a measurable populace whose properties are to be concentrated to pick up data about the entire (Merriam, 2003). The sample in this review will be gotten utilizing the Israel recipe where a certainty level of $90 \%$ will be utilized which as indicated by Saunders, Lewis, and Thornhill (2005) is the level of conviction of the attributes gathered speaking to the qualities of the aggregate populace. A safety buffer of $8 \%$, which the exactness required by scientist for the appraisals produced using test 
will be utilized as well. Accordingly, a specimen size of 105 ought to be an agent of the all-inclusive community. 3.3.1 Criteria for selecting sample size

Table1. Sample Size

\begin{tabular}{llll}
\hline Acc Accuracy (+/-) (Margin of error) & Confidence Level & & $99 \%$ \\
& $90 \%$ & $95 \%$ & 16576 \\
$\mathbf{1}$ & 6765 & 9604 & 4144 \\
$\mathbf{2}$ & 1691 & 2401 & 1848 \\
$\mathbf{3}$ & 752 & 1067 & 1036 \\
$\mathbf{4}$ & 413 & 600 & 663 \\
$\mathbf{5}$ & 271 & 384 & 166 \\
$\mathbf{1 0}$ & 68 & 96 & 41 \\
$\mathbf{2 0}$ & 17 & 24 & \\
\hline
\end{tabular}

(Source: Researcher, 2019)

According to Israel (2009) and Mugenda and Mugenda (2003) the following formula for sample size determination

should be used; $n=p(1-p)\left(\frac{z}{d}\right)^{2}$ Where:

$\mathbf{n}=$ sample size

$\mathbf{z}=$ the table value for the level of confidence, for instance $\mathbf{9 5 \%}$ level of confidence $=\mathbf{1 . 9 6}$ while $\mathbf{9 0 \%}$ level of confidence $=1.645$.

$\mathbf{d}=$ margin of error

$\mathbf{p}=$ proportion to be estimated, Israel (2009) and Mugenda and Mugenda (2003) recommends that if one doesn't know the value of $\mathrm{p}$ then one assumes $\mathrm{p}=0.5$.

Therefore, the sample size of this study is calculated as follows:

$$
105=0.5(1-0.5)\left(\frac{1.645}{0.08}\right)^{2}
$$

\subsection{Data Collection}

The Research utilized bot optional and essential information. Auxiliary information was gotten from the Kisii County handbooks and records put away in the County's information base while essential information was gathered utilizing surveys which contained questions intended to evoke information as per the exploration questions. The polls was sent to the respondents under a survey sending letter joined by a presentation letter from the University. The survey contained both open and close finished inquiries. In the event of the nearby finished inquiries, a fivepoint Likert-sort scale, positioning from 1 (Strongly deviate) to 5 (Strongly concur) was utilized for every one of the variables with 5 being the most grounded/most noteworthy. The utilization of surveys is advocated as they offer a compelling method for gathering data from an expansive specimen in a limited capacity to focus time and at a diminished cost than different techniques.

\subsection{Data Analysis}

After information has been gathered through surveys, it was set up in preparation for examination by altering, dealing with clear reactions, coding, sorting and entering into Statistical Package for Social Sciences (SPSS Version 21) PC programming for analysis. Information was broken down utilizing both quantitative and subjective strategy for information analysis. In particular, enlightening measurements included frequencies while inferential insights included ANOVA and relapse analysis. The factual bundle for sociologies (SPSS) was utilized to direct illustrative and in addition inferential measurements. As indicated by Trochim (2006) elucidating measurements are utilized to depict the fundamental highlights of the information in an examination or study. They give basic rundowns about the specimen and the measures. Together with straightforward designs analysis, they shape the premise of intents and purpose each quantitative analysis of information. Moreover, according to Hsieh and Shannon (2005) subjective substance analysis is favoured and enables researchers to comprehend social reality in a subjective in logical way. 


\subsection{FINDINGS \& DISCUSSIONS}

Table 2 Descriptive Statistics for Public participation on budget implementation

\begin{tabular}{lccc}
\hline Public participation & Mean & $\begin{array}{c}\text { Std. } \\
\text { Deviation }\end{array}$ & Analysis N \\
\hline $\begin{array}{l}\text { It is a fundamental Constitutional requirement that the public be } \\
\text { involved in their County's budget implantation. }\end{array}$ & 4.434 & 0.974 & 105 \\
$\begin{array}{l}\text { Public participation in County's decision making process is vital for } \\
\text { proper budget implementation. }\end{array}$ & 4.236 & .746 & 105 \\
$\begin{array}{l}\text { In several occasions the public has not been involved in the process of } \\
\text { budget making of this County. }\end{array}$ & 2.051 & .860 & 105 \\
$\begin{array}{l}\text { Public's opinion concerning budget is always watered down by the } \\
\text { politician in this County. }\end{array}$ & 1.442 & 105 \\
$\begin{array}{l}\text { There have well established structures for public participation in the } \\
\text { County's decision making process which include the budget making. }\end{array}$ & .732 .342 & 105 \\
\hline
\end{tabular}

The results in the table 2 above show that the respondents agree that public participation is a fundamental Constitutional requirement that the public be involved in their County's budget implantation (mean 4.434), Public participation in County's decision making process is vital for proper budget implementation (mean 4.236) and that Public's opinion concerning budget is always watered down by the politician in this County (4.442). However, the respondent disagree that in several occasions the public has not been involved in the process of budget making of this County (mean 2.051) and that there are well established structures for public participation in the County's decision making process which include the budget making (mean 2.342). The smaller standard deviation relative to the mean implies that there is no significant difference between the sample means and there for the mean is the appropriate model that represents the data.

To establish variables under Public participation effect on budget implementation factor analysis was done. Factors (several explanatory variables) were identified since they were perceived to influence budget implementation and were categorized public participation factors. The preliminary tests employed the use of Kaiser Mayer-Olkin (KMO) and Barlett's test. In this case, KMO measures the sampling adequacy which should be greater than 0.5 for a satisfactory analysis to proceed. Table 3 shows that the KMO measure is .593 which is significant at $\mathrm{p}<.001$ an indication that the Barlett's test of sphericity is significant.

Table 3 Kaiser-Meyer- Olkinand Bartlett's Test

\begin{tabular}{lrr}
\hline & \multicolumn{2}{c}{ KMO and Bartlett's Test } \\
\hline Kaiser-Meyer-Olkin Measure of Sampling Adequacy. & .593 \\
& Approx. Chi-Square & 640.173 \\
Bartlett's Test of Sphericity & df & 104 \\
& Sig. & .000 \\
\hline
\end{tabular}

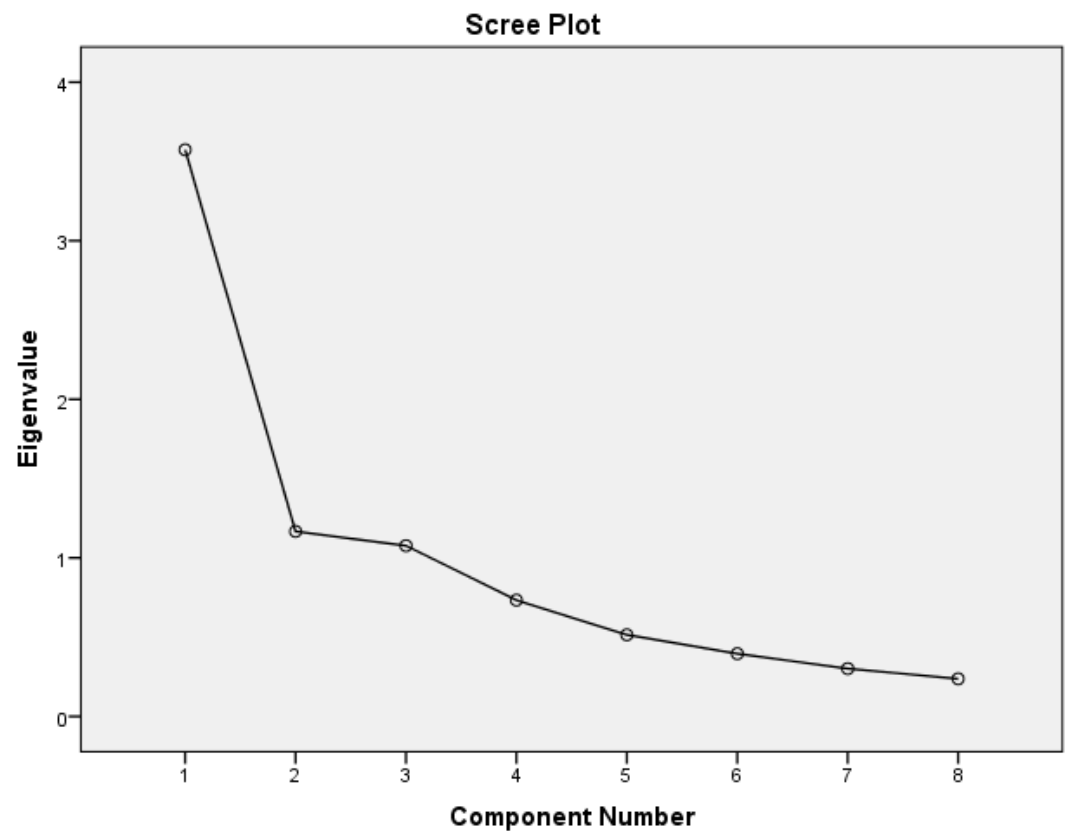

By graphing the eigenvalues the relative importance of each variable becomes apparent. There are a few variables with quite high eigenvalues and other variables have relatively low eigenvalues, and so this graph has a 
very characteristic shape. There is a sharp descent in the curve followed by a tailing off. The cut off point for selecting variables is at the point of inflexion of this curve. From the plot we can extract variables with eigenvalues above one. To establish the priority variables influencing budget implementation, public participation variables were subjected to factor analysis procedure applying varimax as the method for rotation and principal component as a method for extraction of factor components. The results of the factor analysis are shown in table ... of communalities above. The findings show that several enterprise variables of extraction value above .650 as shown in table 4 of communalities below influence budget implementation.

\section{Table 4 Communalities for public participation}

Initial Extraction

It is a fundamental Constitutional requirement that the public be involved in their County's $1.000 \quad .794$

budget implantation.

Public participation in County's decision making process is vital for proper budget 1.000 implementation.

In several occasions the public has not been involved in the process of budget making of this County.

Public's opinion concerning budget is always watered down by the politician in this County. 1.000

There have well established structures for public participation in the County's decision making process which include the budget making.

It is a fundamental Constitutional requirement that the public be involved in their County's 1.000 budget implantation.

Extraction Method: Principal Component Analysis.

The result in table 4 show that five variable had values more than .65 and were extracted for further analysis.

All the variables were extracted and merged to form public participation factor using transformation technique of employing SPSS version 21 to form leadership factor and correlated with budget variables as shown in table 5 below.

Table 5 Correlations of public participation on budget implementation

\begin{tabular}{llc}
\hline Budget implementation & & Public participation \\
\hline Absorption rate of fund & Pearson Correlation & $.432^{* *}$ \\
& Sig. (2-tailed) & .000 \\
& $\mathrm{~N}$ & 105 \\
Number of projects implemented & Pearson Correlation & $.334^{* *}$ \\
& Sig. (2-tailed) & .051 \\
Proper documentation & $\mathrm{N}$ & 105 \\
procurement plans & Pearson Correlation & $.441^{* *}$ \\
& Sig. (2-tailed) & .052 \\
Public satisfaction \& plans & $\mathrm{N}$ & 105 \\
& Pearson Correlation & $.443^{* *}$ \\
\hline
\end{tabular}

*. Correlation is significant at the 0.05 level (2-tailed).

**. Correlation is significant at the 0.01 level (2-tailed).

The results in table 5 above show that public participation positively and significantly influence; Absorption rate of fund, Number of projects implemented, Proper documentation i.e. work plans, procurement plans and Public satisfaction \& ownership at $\left(\mathrm{r}=.432^{* *}, \mathrm{P}<.01\right),\left(\mathrm{r}=.334^{* *}, \mathrm{p}<.05\right),\left(\mathrm{r}=. .441^{* *}, \mathrm{p}<.05\right)$, and $\left(\mathrm{r}=.443^{* *}, \mathrm{p}<.01\right)$ respectively.

All the variable under budget implementation were matched using transformation method using SPSS to form one factor called budget implementation and correlated with public participation as shown in table 6 below; Table 6 Correlation of public participation on budget implementation

\begin{tabular}{llc}
\hline & & Budget implementation \\
\hline \multirow{3}{*}{ Public participation } & Pearson Correlation & $.443^{* *}$ \\
& Sig. (2-tailed) & .05 \\
& $\mathrm{~N}$ & 105 \\
\hline
\end{tabular}

**. Correlation is significant at the 0.05 level (2-tailed).

The results in table 6 above show that public participation positively and significantly influence budget implementation at $\mathrm{r}=.443 * *$ and $\mathrm{p}<.05$ significant level. Calculating the coefficient of determinant $\mathrm{R}$, legislation contributes $19.6 \%$ variability in budget implementation when other factors are held constant.

\subsubsection{DISCUSSIONS}

4.1.2 Legislation on Budget Implementation in Kisii County Government.

The results of analysis showed that the respondent agreed that; County Assembly Members delayed in formulating 
the County Finance Bill, that the MCAs in the County had used statutes to hinder the Governor's and the entire executive's dream in relation to budget implementation, un-matching laws formulated by the County Assembly had made it difficult to properly implement the County budget, Legal progression in terms of formulation of laws concerning budget implementation had not kept pace with the dynamism of the devolved government and lastly they agreed that the extent to which the County budget would be fully implemented depended on the Laws formulated by the County Assembly.

Further analysis revealed that; participatory budgeting positively and significantly influenced budget implementation at $\mathrm{r}=.443^{* *}$ and $\mathrm{p}<.05$ significant level. Calculating the coefficient of determinant $\mathrm{R}$, legislation contributes $19.6 \%$ variability to budget implementation when other factors are held constant.

These finding are in agreement with many scholars; Richard et al. (2001), argues that viable spending administration starts with an unmistakable appropriation of obligations and inside the participatory, and between the diverse levels of government, and a precisely adjusted division of forces between the official branch of governments and the parliament. For this reason, the lawful system must be obviously outlined. Rebecca et al. (2011), notes that the spending cycle commences with the planning strategy, where the government which has administrative oversight, plans for the utilization of the future year's assets as per approach needs. Odhiambo (2013), argues that County enactments controlling the conveyance of administrations by the separate offices are yet to be placed in place.

\subsection{SUMMARYOF THE FINDINGS, CONCLUSION AND RECOMMENDATION 5.1. Summary of findings. \\ 5.1.1 Participatory budgeting on Budget Implementation in Kisii County Government.}

Participatory budgeting positively and significantly influence budget implementation at $\mathrm{r}=.443 * *$ and $\mathrm{p}<.05$ significant level. Calculating the coefficient of determinant $\mathrm{R}$, legislation contributes $19.6 \%$ variability to budget implementation when other factors are held constant.

\subsection{Conclusion}

Participatory budgeting positively and significantly influences budget implementation contributing 19.6\% variability to budget implementation when other factors are held constant. Public participation positively and significantly influences budget implementation contributing $21.3 \%$ variability in budget implementation when other factors are held constant.

\subsection{Recommendation}

The county assembly should speed up the sanctioning of all enactments relating to county government funds' budgeting and administration conveyance to give an appropriate lawful structure to spending execution through public participatory procedures.

\section{REFERENCE}

American Public Human Services Association (2014). Budget and Finance Guidance; Implementation: How does an agency implement an effective approach to budget and finance?

Anthony, R.N. and Govindarajan, V. (2007) Management Control Systems (12th Edition). New York: McGraw Hill.

Auditor General of Canada (2010) Human Resource Capacity; Government of Nunavut: 2010 March Report of the Auditor General of Canada.

Babcock-Daley D., Wright S., Miracle K., Resta K., Amanda M., Rumberg M., Holsneck S. (2003). Strategic Workforce Planning: County of Fairfax, Virginia.

Carol Ebdon and Aimee L. Franklin (2005). Are we all touching the same camel? Exploring a model of participation in budgeting. The American Review of Public Administration, 35 (168), pp. 32-49.

Cooper, D.R. \& Schindler, P.S., (2006). Business Research Methods, $9^{\text {th }}$, edition. McGraw-Hill Publishing, Co. Ltd. New Delhi-India.

Constitution of Kenya, 2010

GIZ (2010). Learning from the South: Participatory budgeting worldwide, an invitation to global cooperation," No. 25. Available at: http://www.buergerhaushalt.org/sites/default/files/downloads/LearningfromtheSouthParticipatoryBudgetingWorldwide-Study 0.pdf.

Hsieh \& Shannon (2005). Three Approaches to Qualitative Content Analysis: Sage Journal

Josh Lerner and Donato Secondo (2012). By the people, for the people: participatory budgeting from the bottom up in North America: Journal of Public Deliberation, 8(2).

Kombo, D, Tromp, D (2006): Proposal and Thesis Writing- An Introduction. Paulines Publications, Nairobi.

Lakin J. (2013). Public Participation in Kenya: County Budget and Economic Forums - Principles and Options: Budget Brief No.21: International Budget Partnership. 
Maskin E. and Sjostrom T. (2001). Implementation Theory:

Merriam, W. (2003). Collegite Dictionary. Springfied Massachusets: $11 \mathrm{Ed}$.

Mugenda, Olive M. \&Mugenda, Abel G. (2005). Research Methods: Quantitative and Qualitative Approaches, Acts Press, Nairobi-Kenya.

Nivek K. Thompson (2012). Participatory budgeting - the Australian way," Journal of Public Deliberation Vol. 8: Issue 2, article 5. Available at: http://www.publicdeliberation.net/jpd/vol8/iss2/art5; Accessed on March 22, 2014

Office of the Budget controller of Kenya Report, June 2013

Public Finance Management (PFM) (2013). Public Participation Under Kenya's New Public Financial Management Law and Beyond.http://internationalbudget.org/wp-content/uploads/PFM-Brief-.pdf. Accessed on March 22, 2014.

Stephanie McNulty (2012). An Unlikely Success: Peru's Top-Down Participatory Budgeting Experience. Journal of Public Deliberation: Vol. 8: Issue 2, article 4. Available at: http://www.publicdeliberation.net/jpd/vol8/iss2/art4. Accessed on March 22, 2014.

Trochim, W. M (2006). The research methods knowledge base (2 ${ }^{\text {nd }}$ ed). Cornell University: Atomic Dog Publishing.

Yan Wu and Wan Yeng (2012). Does participatory budgeting improve the legitimacy of the local government? A comparative case study of two cities in China," The Australian Journal of Public Administration Vol. 71 (2), 2012, pp. 122-135. 